\title{
Los Procesos Lectores Caso de la Institución Educativa Marco Antonio Quijano Rico
}

\section{The reading processes \\ case of the educational institution Marco Antonio Quijano Rico}

Fecha de recepción: 15 de febrero de 2017

Fecha de aprobación: 10 de septiembre de 2017

\begin{abstract}
Alba Paola Rodríguez Barrera* Elsa Yasmin Balaguera Celis** Vilma Gorety Moreno Suárez ***
\end{abstract}

Artículo de investigación científica y tecnológica

\section{Resumen}

El análisis acerca del proceso lector en la población de estudiantes de la Institución Educativa Marco Antonio Quijano Rico de la ciudad de Sogamoso, se realizará mediante investigación cualitativa de tipo investigación-acción, tomando como base las dificultades lectoras que presentan los estudiantes en cuanto a bajo nivel de comprensión, análisis y vocabulario. Dicho análisis contará con la participación en actividades proclives a clasificar cada una de las falencias y encontrar alternativas que conlleven a soluciones prontas y efectivas durante el proceso de formación académica. Asimismo se desarrollará una propuesta metodológica constructivista y moderna que permita a los docentes considerar estas herramientas para orientar las prácticas educativas en beneficio del proceso de enseñanza-aprendizaje, incluyendo a los padres de familia.

Palabras clave: Lectura, Escritura, Comprensión lectora, Ruralidad, Didáctica.
*Institución Educativa Marco Antonio Quijano Rico, Boyacá-Colombia albita.rodriguezb@gmail. com

**Institución Educativa Marco Antonio Quijano Rico, Boyacá-Colombia yasminbalaguera@gmail.com *** Institución Educativa Marco Antonio Quijano Rico, Boyacá-Colombia vilmagoretymorenosuarez@ gmail.com

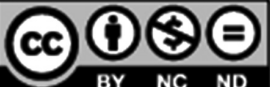




\section{Abstract}

The analysis about the reading process in the student population at the Educational Institution "Marco Antonio Quijano Rico" (Sogamoso, Colombia) will be a qualitative investigation of the research-action type, taking as a base the reading difficulties that the students present in terms of low level of comprehension, analysis and vocabulary. Such analysis will have the participation in activities prone to classify each of the shortcomings and find alternatives that lead to prompt and effective solutions during the academic training process. Likewise, a constructivist and modern methodological proposal will be developed that allows teachers to consider these tools to guide educational practices for the benefit of the teaching-learning process, including parents.

Keywords: Reading, Writing, Reading comprehension, Rurality, Didactics. 


\section{Introducción}

El proceso lector se considera como el camino cognitivo, los pasos que siguen los estudiantes al leer y que les permite comprender. Lo que sucede en este "camino" o "pasos" que se den al momento de leer, es lo que determina que los estudiantes comprendan bien un texto o que se les dificulte.

Estos pasos están relacionados con procesos mentales, estrategias y actividades que facilitan para alcanzar las competencias lectoras, entendidas como la capacidad individual, que tienen los estudiantes para comprender, utilizar y analizar textos escritos, con el fin de lograr sus objetivos personales; desarrollar sus conocimientos y posibilidades, y participar plenamente en la sociedad (Organización para la Cooperación y el Desarrollo Económico, 2009).

Se consideran buenos lectores, aquellos que comprenden lo que leen para su beneficio (León, 2004), para convertirse en lectores autónomos, es necesario enseñarles cómo hacerlo, es decir, orientarlos en cada etapa, realizando una serie de actividades que les permita ir construyendo el significado del texto, comprenderlo y establecer vínculos con la lectura (Solé, 1998).

El problema de la lectura parece agudizarse aún más en contextos rurales en donde la pobreza y el poco acceso a sistemas educativos tecnificados. Dentro del núcleo familiar, se deja a los niños sin el apoyo que se requiere para alcanzar los logros educativos. Como lo afirma Bravo (1996), una dificultad para la adquisición de la lectura radica en las limitadas oportunidades de alfabetización ofrecidas a los niños antes y durante su aprendizaje formal de la lectura, teniendo en cuenta el nivel socioeconómico de las familias, sus ingresos mensuales y el nivel educativo de los padres, estas son variables predictivas de las habilidades prelectoras de niños escolarizados. Siguiendo esta línea, Phillips y Lonigan (2009) complementan esta afirmación al encontrar que es posible predecir la competencia lectora de los niños desde temprana edad, si se conocen las prácticas de alfabetización de las familias, el número de libros que hay en casa, el hábito de lectura en los padres y la inclusión de los niños en las actividades diarias familiares.

Para la investigación, se utilizó como sustento teórico un enfoque cognitivo basado en los procesos lectores de Cuentos (2010), a saber: perceptivos, léxicos, sintácticos y semánticos; con el findefortalecerlas competenciaslectoras de los estudiantes en el contexto rural de la institución educativa. El diseño se enmarcó dentro de la investigación acción (I.A) descrita por Elliot (2000), cuya finalidad es problematizar una realidad que agobia el quehacer educativo, y permite la reflexión sobre las dificultades $\mathrm{O}$ potencialidades. La investigación se llevó a cabo en tres fases metodológicas basadas en el enfoque cualitativo, por medio de procesos de observación e indagación como: grupo focal, encuestas, y talleres de intervención pedagógica, para identificar las problemáticas y plantear posibles soluciones a las mismas.
Se consideran buenos lectores, aquellos que comprenden lo que leen para su beneficio (León, 2004), para convertirse en lectores autónomos. 
A partir de la intervención, se lograron avances significativos en las habilidades lectoras, desde los procesos perceptivos, movimientos sacádicos y reconocimiento de fonemas, procesos léxicos, pautas para decodificar una palabra (léxico y/o fonético); proceso sintáctico, orden de las palabras en una oración para tener una idea con sentido; proceso semántico, corresponde a la comprensión de textos cortos, las cuales estan relacionadas con el desarrollo congnitivo debido al uso de estrategias que estaban encaminadas a proceso metacognitivos (Martínez-Bernal, Sanabria-Rodríguez \& López-Vargas 2016).

\section{Teorías del conocimiento tratado}

Según Touriñan (1989),

"El objetivo de las teorías del conocimiento, cuando se analiza el conocimiento de la educación, es establecer un esquema de interpretación que nos permita, con criterio lógico, comprender la distinta consideración que el conocimiento de la educación tiene o ha tenido. Se intenta describir las propiedades que permiten caracterizar diferentes momentos de la consideración de la educación como objeto de conocimiento" (pp. 83-84).

Este objetivo busca saber cómo se considera la educación como objeto de conocimiento. Por tanto, lo que interesa especialmente es entender la propia transformación de la educación como objeto de conocimiento y su progresiva adecuación al ámbito que estudia.
Dentro de estas teorías, la lectura desempeña el rol más importante en el aprendizaje.

La lectura se considera como el pilar del saber, sí se hace de forma correcta y con sentido, ya que permite que los niños accedan al conocimiento para que obtengan las competencias necesarias para la adquisición de aprendizajes y un posterior desenvolvimiento como miembro de una sociedad (Castellanos et al., 2013). Piaget, citado en Feo, (2010) menciona que "la lectura se debe enseñar a partir de una pedagogía lúdica y más exactamente el juego, el cuento como recurso para enseñar la lectura facilita el desarrollo de la parte recreativa en el niño" (p.23). Es así como la lectura tiene diferentes connotaciones las cuales buscan clarificar el acto como tal, y que le permita al lector buscar el que mejor se acomode a sus necesidades y gustos, donde realicen una lectura global de la realidad que les permita una construcción y apropiación de saberes (Mariño, Pulido \& Morales 2016).

Chambers (2008) menciona que:

"Leer es un drama de tres actos (Tabla 1). El primer acto es la selección: elegir qué leer, dónde leerlo, cuándo leerlo. El segundo acto es la lectura de lo que hemos elegido leer, y es un ejercicio que requiere que nos entreguemos a él, nos dejemos absorber por el libro, incluso nos volvamos antisociales por periodos considerables. El tercer acto es la reconstrucción que se refiere a rehacer, reformar, reestructurar" (p.187). 
Tabla 1

Actos para una buena lectura

\begin{tabular}{|c|c|c|}
\hline ACTOS & & CARACTERÍSTICAS \\
\hline \multirow{3}{*}{1} & \multirow{3}{*}{ Selección } & $\bullet$ Qué leer \\
\hline & & - Cuándo leer \\
\hline & & - Dónde leer \\
\hline 2 & Lectura elegida & $\begin{array}{c}\text { Entregarse a la lectura por periodos largos. } \\
\bullet \quad \text { Rehacer }\end{array}$ \\
\hline \multirow[t]{2}{*}{3} & \multirow[t]{2}{*}{ Reconstrucción } & - Reformar \\
\hline & & - Reestructurar \\
\hline
\end{tabular}

Fuente: Chambers, (2008) p. 189

Solé (1995) sostiene que "leer es un proceso de interacción entre el lector y el texto, proceso mediante el cual el primero intenta satisfacer (obtener una información pertinente) para los objetivos que guían su lectura" p. 17. Esto hace obligatoria la presencia de un lector activo que enjuicia y examina el texto, y que debe existir propósito para leer, es decir, que siempre se lee para algo, para alcanzar un objetivo o una finalidad. Queda claro entonces que leer no se debe convertir en una mera decodificación sino que se debe tener un sentido guiado por el gusto de aprender.

De otra parte, Ferreiro y Teberosky (2005) afirman que el lector debe ser crítico de los textos que lee, para que así pueda encontrar el significado de la palabra escrita, es decir, la lectura es un acto que permite que el ser humano le dé sentido y coherencia a lo que el autor quiere manifestar en su escrito, por lo tanto, el lector en el momento de leer, debe buscar sentido de lo que se quiere expresar.
Para Ferreiro (2005), la lectura es la actividad que permite identificar, decodificar y analizar lo que otra persona quiere decir, pero se debe tener en cuenta que esta no solo es un acto donde el lector decodifica signos gráficos, sino se debe buscarle un sentido al texto y transformar los conocimientos previos por los conocimientos actualmente aprendidos.

Por otro lado, Teberosky (2002), se refiere a la lectura como el medio por el cual el ser humano procesa, de manera ordenada, la información recibida a través de códigos gráficos, integrando otros procesos como la comprensión y el análisis de la información; del mismo modo, señala, que a través del tiempo el ser humano ha inventado máquinas para mejorar su calidad de vida, como la rueda, la computadora o el propio automóvil, pero será la lectura la que en realidad lo llevará a comprender la ciencia y el sentido propio de la vida.

\section{El proceso lector}

La lectura comprensiva está determinada por una cadena de operaciones mentales,
Solé (1995) sostiene que "leer es un proceso de interacción entre el lector y el texto, proceso mediante el cual el primero intenta satisfacer (obtener una información pertinente) para los objetivos que guían su lectura" 
que hacen que esto sea probable. Por lo tanto, es indispensable comprender esta visión de la lectura, sobre todo cuando se habla de problemas de lectura, ya que esto sugiere que uno o varios procesos lectores no se está desempeñando de forma adecuada, por lo tanto, la participación y la recuperación deben orientarse a la adquisición de estos procesos.

Es necesario fomentar unas acciones cognitivas que impliquen el desarrollo de procesos lectores. Para Cuetos (2010), los procesos lectores están organizados en cuatro actos. (Tabla 2):

Tabla 2

Etapas del proceso lector

\begin{tabular}{ll}
\hline PROCESOS & \multicolumn{1}{c}{ DESCRIPCIÓN } \\
\hline Perceptivos & $\begin{array}{l}\text { Percepción visual de } \\
\text { letras y palabras. } \\
\text { Lecodificar las palabras } \\
\text { escritas. }\end{array}$ \\
Sintácticos & $\begin{array}{l}\text { Establecer relaciones } \\
\text { sintácticas con el texto } \\
\text { Comprensión de lectura } \\
\text { propiamente dicha. }\end{array}$ \\
\hline
\end{tabular}

Fuente: Cuetos, 2010. P.29

En los Procesos Perceptivos, la lectura inicia con la percepción visual de las letras y de las palabras escritas, siendo el principal de los procesos. Está percepción está igualmente limitada por los denominados movimientos sacádicos, es decir, movimientos que realizan los ojos a lo largo de los renglones. El ojo no hace un rastreo como si fuera un escáner; los movimientos sacádicos son saltos cortos que el ojo ejecuta en puntos desiguales de la línea escrita. La percepción visual es el proceso inicial lector.
Los Procesos Léxicos son las operaciones cognitivas encargadas de leer palabras, es decir, de "decodificar" las palabras escritas. Los procesos léxicos son realmente significativos porque condicionan la velocidad lectora y la comprensión, aunque su tarea, no es propiamente la comprensión, sino modificar los signos escritos (letras) en fonemas y palabras orales o mentales, si se hace lectura silenciosa. En lenguas transparentes, como el español, donde existe una relación casi total entre los grafemas y los fonemas, existen dos formas de leer palabras: la ruta fonológica y la ruta léxica.

Los Procesos Sintácticos, son los encargados de construir las relaciones sintácticas entre los elementos del discurso escrito. Estas relaciones están asociadas especialmente al orden en el que están escritas, el uso de los signos de puntuación y, sobre todo, el uso de las palabras funcionales, como preposiciones y conjunciones principalmente. Los procesos sintácticos pueden cambiar el sentido de una oración sin apenas cambiar las palabras o sin ni siquiera cambiarlas.

Al final de la cadena de procesos lectores, se encuentran los Procesos Semánticos, es decir, los procesos de comprensión de la lectura propiamente dichos. La comprensión está referida a palabras, oraciones y textos de diferente longitud. La comprensión lectora implica extraer el significado de lo escrito, pero también la capacidad de deducir información que no está explícitamente marcada en el texto. Esto ocurre, por ejemplo, en las fábulas, 
donde la moraleja, es una información que se debe deducir de la historia, pero no siempre está destacada claramente en el contenido del texto. Finalmente, la comprensión lectora, integra parte de la información en la memoria del lector.

\section{Estrategias de lectura}

Según Solé (1994), la lectura está conformada por tres momentos que conllevan a la formación del proceso lector (Figura 1): Primer momento, de preparación anímica, afectiva y de aclaración de propósitos. Segundo momento, la actividad misma, que comprende la aplicación de herramientas de comprensión en sí; para la construcción del significado. Tercer momento, la consolidación del mismo; haciendo uso de otros mecanismos cognitivos para sintetizar, generalizar y transferir dichos significados.

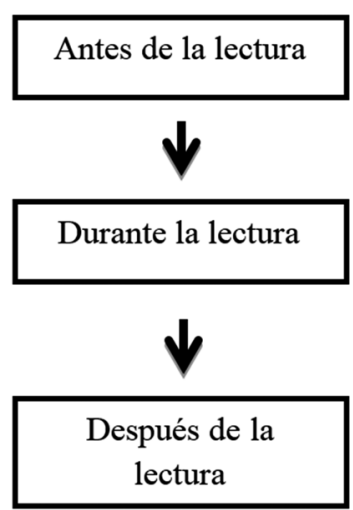

Figura 1. Momentos de formación del proceso lector.

Siendo la lectura un proceso que desarrolla habilidades cognitivas, afectivas y conductuales, debe ser tratada principalmente por momentos o pasos. En cada momento, debe desarrollarse diferentes estrategias con propósitos definidos dentro del mismo proceso lector. El proceso lector, se subdivide en tres subprocesos: antes de la lectura, durante la lectura y después de la lectura (Solé, 1994):

Antes de la lectura. Todo proceso de aprendizaje significativo debe ser interactivo, igualmente en la lectura primero debe crearse las condiciones de carácter afectivo, es decir, el encuentro emotivo de los interlocutores: Uno que expone sus ideas, y el otro que aporta su conocimiento previo motivado por interés propio.

Esta es en síntesis la dinámica delalectura. En esta etapa y con las condiciones previas, se enriquece dicha dinámica con otros elementos sustantivos: el lenguaje, las interrogantes e hipótesis, recuerdos evocados, familiarización con el material escrito, una necesidad y un objetivo de interés del estudiante, no del maestro únicamente.

Durante la lectura. Propone seguir una serie de pasos que lleven a una interpretación del texto. En este momento, es necesario que los estudiantes hagan una lectura de reconocimiento, en forma individual, para familiarizarse con el contenido general del texto.

En seguida, pueden leer en pares o pequeños grupos, y luego intercambiar opiniones y conocimientos en función del propósito de la actividad lectora.

Al respecto, conviene decir que siendo el quehacer una función integradora, este es un auténtico momento para que los estudiantes trabajen los contenidos
Según Solé (1994), la lectura está conformada por tres momentos que conllevan a la formación del proceso lector 


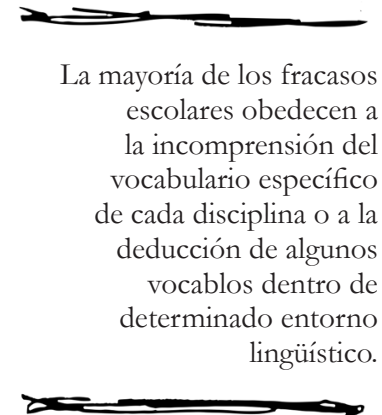

transversales, valores, normas y toma de decisiones; sin depender exclusivamente del docente. Las funciones son específicas, del apoyo a la actividad en forma sistemática y constante.

Después de la lectura. De acuerdo con el enfoque socio-cultural propuesto por Vygotsky, (1979), la primera y segunda etapa del proceso propiciarán un ambiente socializado y dialógico, de mutua comprensión. La actividad ha de instrumentalizar el lenguaje como herramienta eficaz de aprendizaje, de carácter inter-psicológico. En esta etapa, todavía está vigente la interacción y el uso del lenguaje, cuando se les propone a los estudiantes la elaboración de esquemas, resúmenes, comentarios, etc.

Aquí, el trabajo es más reflexivo, crítico, generalizador, meta-cognitivo, metalingüístico; o sea, que el aprendizaje entra a un nivel intrasicológico. La experiencia activada con el lenguaje se convierte en imágenes de carácter objetivo; los que vienen a integrarse a los esquemas mentales del sujeto, para manifestarse luego en su personalidad.

\section{Niveles de comprensión lectora}

Los niveles de comprensión deben interpretarse como una transformación de pensamiento que se da en el proceso de la lectura, se fomentan secuencialmente, en el transcurso en que se entiende la comprensión como un proceso de interacción entre el texto y el lector, Strang (1965), Jenkinson (1976) y Smith (1989) explican la compresión en los niveles literal, inferencial y crítico.
Nivel de comprensión literal. Leer literalmente es elaborar acorde al texto. Pretende respuestas sencillas, que están evidentes en el texto escrito, pero solicita conocer las palabras. De este nivel, forman parte: la lectura literal en un nivel primario, el cual se enfoca en las ideas y referencias que están claramente expuestas en el texto, por observación trayendo a la memoria los hechos.

Esta observación puede ser: de detalle, que establece nombres, personajes, tiempo y lugar de un relato; de ideas principales: la idea más relevante de un párrafo o del relato; de secuencias: establece la sucesión de las acciones; por comparación: identifica caracteres, tiempos y lugares categóricos; de causa o efecto: establece razones categóricas de algunos hechos o acciones. Hacemos una lectura elemental: seguimos paso a paso el texto, lo ubicamos en cierta época, lugar, determinamos personajes principales y secundarios; nos centramos en el vocabulario, las expresiones metafóricas.

La mayoría de los fracasos escolares obedecen a la incomprensión del vocabulario específico de cada disciplina o a la deducción de algunos vocablos dentro de determinado entorno lingüístico. El estudiante debe ejercitarse en el contenido semántico de las palabras y cuál es el sentido correcto de las que aparecen en el diccionario en consonancia al significado completo de la frase en la cual se halla incluido. Lectura literal en profundidad, realizamos una lectura más acentuada, profundizando en el entendimiento del texto, analizando las ideas que siguen 
el tema principal, elaborando cuadros sinópticos, mapas conceptuales y síntesis. La mayoría de estas técnicas son más adecuadas para textos expositivos que para textos literarios.

Nivel inferencial. Se aviva el conocimiento previo del lector y se formulan hipótesis referente a el contenido del texto iniciando por los indicios, estas se van revisando o reformulando durante la lectura. La lectura inferencial o interpretativa es igual a la "comprensión lectora", ya que es una interacción inquebrantable entre el lector y el texto, se emplea la información del texto y se integra con lo que se sabe para sacar conclusiones (Smith, 1989). Se indaga para construir relaciones que van más allá de lo leído, expresado en el texto más ampliamente, anexando informaciones y experiencias previas, vinculando lo leído con nuestros saberes previos, formulando hipótesis y nuevas ideas.

El objetivo del nivel inferencial será la producción de conclusiones. Este nivel puede contener las operaciones de: inferir detalles complementarios, que según las hipótesis del lector, pudieron haberse contenido en el texto para hacerlo más atrayente, informativo y persuasivo, y deducir ideas principales, no incluidas claramente; inferir secuencias, sobre hechos que pudieron haber sucedido si el texto hubiera terminado de otra forma; deducir relaciones de causa y efecto, elaborando conjeturas sobre las motivaciones y sus relaciones en el tiempo y el lugar.

Se pueden hacer hipótesis sobre las causas que impulsaron al autor a incorporar algunas ideas, palabras, caracterizaciones, acciones; pronosticar hechos sobre la base de una lectura incompleta, a propósito o no; aclarando un lenguaje simbólico, para concluir la importancia literal de un texto.

Nivel crítico. En este nivel de comprensión, el lector, posteriormente de la lectura, confronta el concepto del texto con sus saberes y destrezas; después, emite una opinión críticovalorativa y la expresión de criterios personales sobre lo que lee. Puede dirigirse en un nivel más avanzado a decidir los propósitos del autor del texto, lo que necesita un procesamiento cognitivo más amplio de la información. Se emiten juicios sobre el texto leído, lo aprobamos o rechazamos pero con soportes.

La lectura crítica tiene una condición evaluativa donde influyen la formación del lector, su criterio y conocimientos de lo leído. Los procesos toman en cuenta cualidades de exactitud, aceptabilidad, posibilidad. Los juicios pueden ser: de realidad o fantasía: según la práctica del lector con las cosas que lo circundan o con los relatos o lecturas; de adecuación y eficacia: relacionar lo que está escrito con otras fuentes de información; de apropiación: requiere evaluación relativa en las diferentes partes, para asimilarlo; de rechazo o aceptación: depende del código moral y del sistema de valores del lector.

La formación de seres críticos, es una exigencia para la escuela y solo se puede promover en un clima agradable y de libre expresión, en el cual los alumnos puedan analizar sus opiniones con
La lectura crítica tiene una condición evaluativa donde influyen la formación del lector, su criterio y conocimientos de lo leído. Los procesos toman en cuenta cualidades de exactitud, aceptabilidad, posibilidad. 
calma y respetando a su vez la de sus compañeros.

\section{Materiales y métodos Población y muestra}

La investigación se desarrolló en la Institución Educativa Integrada Marco Antonio Quijano Rico del Municipio de Sogamoso en el Departamento de Boyacá, plantel oficial conformado por 7 sedes (Escuelas Alto Peñitas, Peña Negra, El Mortiñal, Quebrada Honda, Pilar y Ceibita, San Martín y el Hatillo). Esta institución cuenta con una población estudiantil de 280 estudiantes desde grado preescolar hasta grado 11.

Los estudiantes evaluados fueron los niños y niñas de la sede Pilar y Ceibita (Escuela unitaria; 14 estudiantes: una docente atiende todos los grados desde preescolar hasta quinto y los niños y niñas de la sede central El Hatillo, Escuela gradual con los grados tercero con una población de 17 estudiantes y grado cuarto, con 22 estudiantes. Los niños y niñas se encuentran entre los 5 y 11 años de edad. La muestra estuvo conformada por 14 estudiantes de la sede Pilar y Ceibita, 17 estudiantes del grado 3 y 21 estudiantes del grado 4 de la sede central el Hatillo, para un total de 52 estudiantes. Los estudiantes se caracterizan por ser muy respetuosos, colaboradores, tímidos y con poca expresión oral.

\section{Metodología}

La estructura metodológica está fundamentada en una investigación de tipo cualitativo, la cual acude a métodos de recolección de datos y encaminados a reconstruir la realidad. El diseño escogido es la investigación acción (IA), el cual se presenta como una metodología de investigación orientada hacia el cambio educativo, que se define por ser un proceso que, de acuerdo con Kemmis y McTaggart (1988), se caracteriza por:

1. Construirse desde y para la práctica.

2. Mejorar la práctica a través de su transformación, al mismo tiempo que procura comprenderla.

3. Demanda la participación de los sujetos en la mejora de sus propias prácticas.

4. Exige una actuación grupal por la que los sujetos implicados colaboran coordinadamente en todas las fases del proceso de investigación.

5. Implica la realización de análisis crítico de las situaciones y se configura como una espiral de ciclos de planificación, acción, observación y reflexión.

\section{Etapa de desarrollo}

Constituye la aplicación directa de los talleres de intervención pedagógica, estos fueron elaborados de acuerdo con la guía PROLEC, propuesta por Cuetos et al. (2010), en donde se manifiesta que el sistema de lectura está formado por cuatro procesos relativamente autónomos, ya que cada uno realiza una función específica de acuerdo con los subprocesos.

\section{Estructura de los talleres}

Los talleres se agruparon teniendo en cuenta los cuatro métodos que intervienen en el proceso lector, y se aplicaron de acuerdo con el grado de escolaridad de los niños. Las pruebas 
se desarrollaron teniendo en cuenta las siguientes actividades:

a. Nombre o sonido de las letras, igualdad y diferencias en palabras y pseudopalabras.

b. Lecturadepalabras ypseudopalabras.

c. Estructura gramatical y signos de puntuación.

d. Comprensión de oraciones y de textos cortos.

\section{Resultados y discusión}

\section{Etapa inicial}

Con la aplicación de los de instrumentos para caracterizar el contexto sociocultural de los estudiantes de los grados tercero y cuarto de la sede el Hatillo y de la sede Pilar y Ceibita, se encontró:

\section{Grupo focal}

Con base en la aplicación del grupo focal, se puede afirmar que la familia es quien ejerce una gran influencia motivacional del niño hacia la lectura, y que el placer por leer no viene innato con los niños, sino que este gusto por la lectura se desarrolla con ambientes motivacionales que deben adecuarse a las habilidades e intereses de los niños, lo que es confirmado por Ferreiro y Teberosky (1979). En este sentido, nos damos cuenta que los mecanismos que brinda la familia para desarrollar el proceso lector son mínimos.

\section{Encuesta a estudiantes}

Los estudiantes que les gusta la lectura son un número muy reducido (13\%) y el resto leen por obligación. En este sentido, se determina que el gusto por la lectura no está muy desarrollado en los estudiantes, ya que no está dentro de las actividades que se realizan diariamente.

\section{Encuesta a padres de familia}

Se encontró que el núcleo familiar están conformado por matrimonios jóvenes que tienen poco tiempo libre, incluso para compartir con sus hijos, porque dentro de sus preocupaciones fundamentales, está el trabajo, los padres trabajan fuera, permaneciendo todo el día ausentes del hogar y de las relaciones escolares de sus hijos. Fue posible identificar que la mayoría de los niños viven en la vereda Pilar y Ceibita, distantes del colegio.

Se evidencia que la mayor parte de los estudiantes no tienen el apoyo de sus padres, ya sea porque están realizando las labores del campo o simplemente porque no saben leer; los que tienen el acompañamiento (86\%), se ve el compromiso por parte de los padres para que sus hijos se superen y tengan una mejor calidad de vida. Por lo tanto, este aspecto refleja que las actividades lectoras son orientadas, en un alto nivel, en el colegio por los docentes.

Sin embargo, se encontró que los padres, a pesar de no tener hábitos lectores y no contar con un programa de lectura, tienen una actitud positiva frente a la misma; pues, más de la mitad la considera como divertida y como un acto que puede permitir obtener conocimientos. Por tanto, el acompañamiento debe ser un trabajo conjunto entre el colegio y la familia.
Con base en la aplicación del grupo focal, se puede afirmar que la familia es quien ejerce una gran influencia motivacional del niño hacia la lectura, $y$ que el placer por leer no viene innato con los niños, sino que este gusto por la lectura se desarrolla con ambientes motivacionales que deben adecuarse a las habilidades e intereses de los niños, lo que es confirmado por Ferreiro y Teberosky (1979). 


\section{Taller diagnóstico}

En el taller diagnóstico, se encontró que existen deficiencias que impiden que los estudiantes realicen ejercicios de lectura que buscan comprender y entender el texto leído. Es así como la mayoría de los estudiantes no reconoce el nombre y sonido de algunas letras del alfabeto y sus combinaciones, y por lo tanto, no comprenden lo leído; su lectura es carencial o disléxica, ya que presentan varios errores en el proceso lector, omiten letras sílabas o palabras, confunden letras o sonidos de formas semejantes (q, c, k, ñ, ll, y, $\mathrm{b}, \mathrm{d}, \mathrm{p}$,). Cambian de lugar las letras o las sílabas, su lectura, en la gran mayoría de los estudiantes, es lenta, arrítmica y arrastrada. Es así como, el 33\% de los estudiantes necesitan apoyo en los procesos semánticos; 25\%, en los procesos léxicos; el $23 \%$, en procesos sintácticos y en procesos perceptivos, el 19\% (Figura 1).
En este sentido, se hace necesario fortalecer cada uno de los procesos cognitivos que intervienen en la lectura, ya que como lo afirma García (1993), cuando se lee un texto con el fin de comprenderlo, la mente realiza un complejo de operaciones o procesos mentales. No es suficiente con la decodificación de signos o letras escritas ni el reconocimiento de palabras y lo que estas significan (procesos léxicos). Estos son procesos necesarios, pero no suficientes para alcanzar una lectura comprensiva. Es preciso también poner en juego conocimientos de tipo sintáctico que ponen en relación las palabras, constituyendo unidades mayores como las oraciones y frases con una determinada estructura y no otra (procesos sintácticos). Además, el lector tiene que comprender el significado de la oración y el mensaje y contenido del texto integrándolo con los conocimientos previos del sujeto (procesos semánticos).

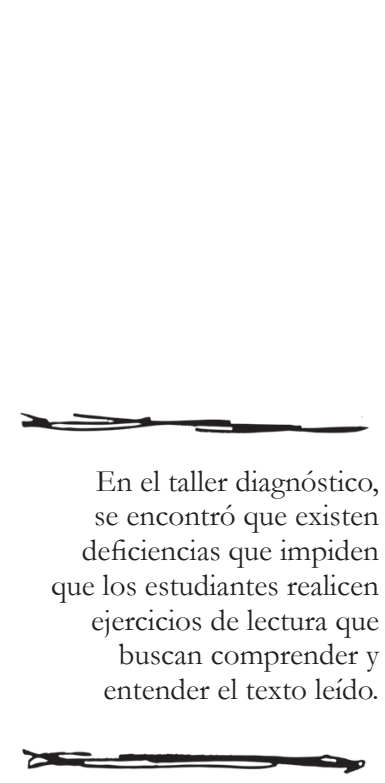

En el taller diagnóstico, se encontró que existen deficiencias que impiden los estudiantes realicen jercicios de lectura que buscan comprender y entender el texto leído.

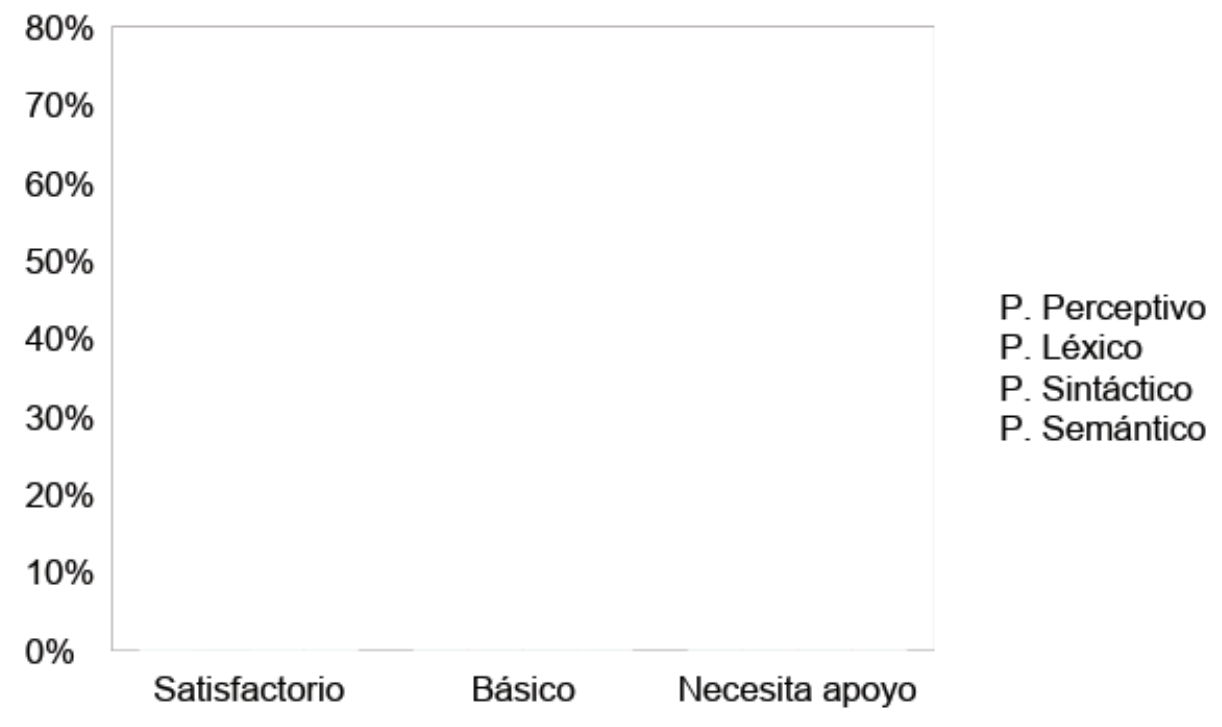

Figura 2. Taller diagnóstico. 


\section{Etapa de Desarrollo}

A partir de los resultados obtenidos en la prueba diagnóstica, se diseñaron los talleres de intervención pedagógica con el fin de fortalecer las falencias encontradas en cada uno de los procesos cognitivos que intervienen en el proceso lector.

\section{Proceso perceptivo}

Con respecto a la observación de los movimientos sacádicos en las tres actividades (Figura 3), se encontró que los estudiantes presentaron una notable mejoría en cuanto a los movimientos oculares, disminuyó el cansancio y lagrimeo de sus ojos. Es así como el $56 \%$ de los estudiantes de acuerdo con la valoración estipulada, se encuentran en un nivel básico, ya que su amplitud visual no es tan limitada, es decir, lograron seguir objetos con sus ojos, realizar ejercicios lectores de izquierda a derecha fijando sus ojos en cada sílaba o palabra que iban leyendo; el $20 \%$ se ubican en un nivel satisfactorio, ya que lograron realizar los ejercicios siguiendo las pautas dadas y no presentaron ninguna molestia física, sin embargo, el $24 \%$ necesitan apoyo, ya que continúan presentando dificultades al realizar los ejercicios planteados, como el no seguir la lectura con el dedo, mover la cabeza y saltar líneas al leer.

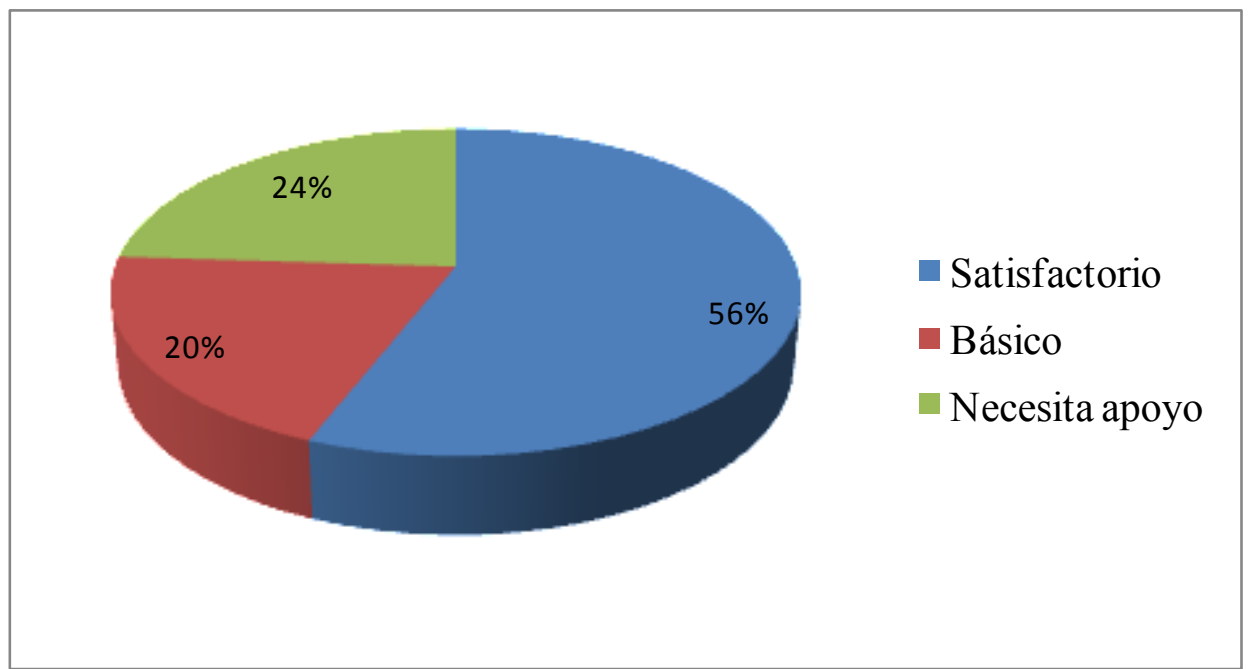

Figura 3. Taller de movimientos sacádicos aplicado a los niños de los grados tercero y cuarto de la sede el Hatillo y Pilar y Ceibita, de la Institución Educativa Marco Antonio Quijano Rico.

Para desarrollar el taller cuyo objetivo fue identificar grafemas y fonemas, se le entregó a los niños varias fichas con palabras partidas para que ellos unieran los pares y formaran las construcciones verbales, y se les presentó una lista de palabras (ascensor, determinar, caliente, electricidad, alimento, molestia, destruir, maestro, plancha, demostración) con el fin de que ellos escribieran la segunda y cuarta letra de cada una de ellas. Mediante un audio, los niños debían escuchar 
con mucha atención los sonidos de cada letra, para poder relacionar los fonemas con su respectivo grafema. En una ficha, los niños debían encontrar la palabra escondida, en unos globos se encuentra las sílabas de una palabra en desorden; ellos deben ordenar las sílabas y encontrar la palabra.

Luego de aplicadas las actividades, el $42 \%$ lograron superar sus falencias en cuanto al reconocimiento de las letras de forma gráfica y fonética, reconocen las letras del alfabeto, las leen de forma rápida y las identifican por el sonido, ya que pueden reconocerlas en una palabra y asociarla de acuerdo con su sonido. Mientras el 35\% aún presentan cierta dificultad, ya que en algunas ocasiones olvida el nombre o sonido de las letras que utilizan con poca frecuencia (w, x, k) y el 23\% se ubicó en el nivel "necesita apoyo", puesto que confunden letras de formas similares (b, d, u, n, p, q), confunden una letra por otra, ya sea gráfica o fonéticamente (b y p, t y d, q y c). (Figura 4).

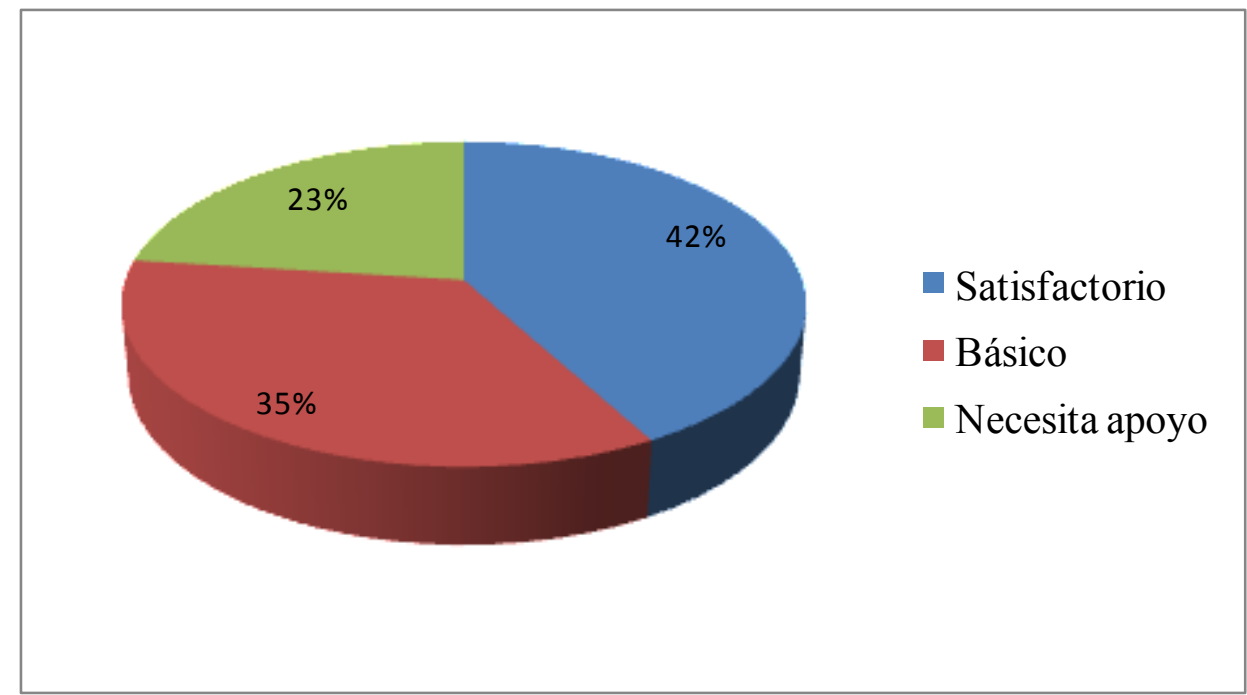

Figura 4. Taller de reconocimiento de grafemas y fonemas aplicado a los niños de los grados tercero y cuarto de la sede el Hatillo y Pilar y Ceibita, de la Institución Educativa Marco Antonio Quijano Rico.

Los resultados permitieron evaluar las variables que preceden el aprendizaje de los procesos lectores. El desarrollo del proceso lector perceptivo en los estudiantes, les permite el conocimiento de las letras y sus sonidos, la memoria verbal y el lenguaje oral
Los resultados permitieron evaluar las variables que preceden el aprendizaje de los procesos lectores. El desarrollo del proceso lector perceptivo en los estudiantes, les permite el conocimiento de las letras y sus sonidos, la memoria verbal y el lenguaje oral; como aquellas competencias que están relacionadas con el éxito del aprendizaje de la lectura y que, a través de este instrumento, se podrá identificar a aquellos estudiantes que presenten deficiencias en estas áreas para que puedan ser intervenidos a tiempo y evitar el fracaso lector (Cuetos, 2010). Por tanto, la identificación de las letras es un paso previo y necesario para el reconocimiento de las palabras y exceso a su significado, que es el objetivo real de la lectura. 


\section{Procesos léxicos}

Para el desarrollo de este taller, una de las actividades realizadas consistió en dar una lista de palabras a los estudiantes, ellos debían señalar de la lista dada, cuáles eran inventadas, o reconocidas como pseudopalabras, esto con el fin de identificar el grado de decisión léxica de cada estudiante, es decir el reconocimiento de palabras que fácilmente podían ser asociadas a un significado.

Se encontró que a un $25 \%$ de los estudiantes se les dificulta encontrar la diferencia entre palabras reales de las inventadas, mientras que el $67 \%$ las logró clasificar de forma rápida, y el $8 \%$ restante expresó que esas palabras podrían existir (figura 5) solo que ellos no las conocían. De este resultado, se puede deducir que es necesario ampliar el vocabulario de los estudiantes, ya que con esto se ayuda a mejorar la comprensión de oraciones y textos cortos, pues al tener un vocabulario más amplio su comprensión será más efectiva, como lo afirma Montealegre y Bohórquez (2000), cuantas más palabras conozca un niño mejor comprenderá un texto.

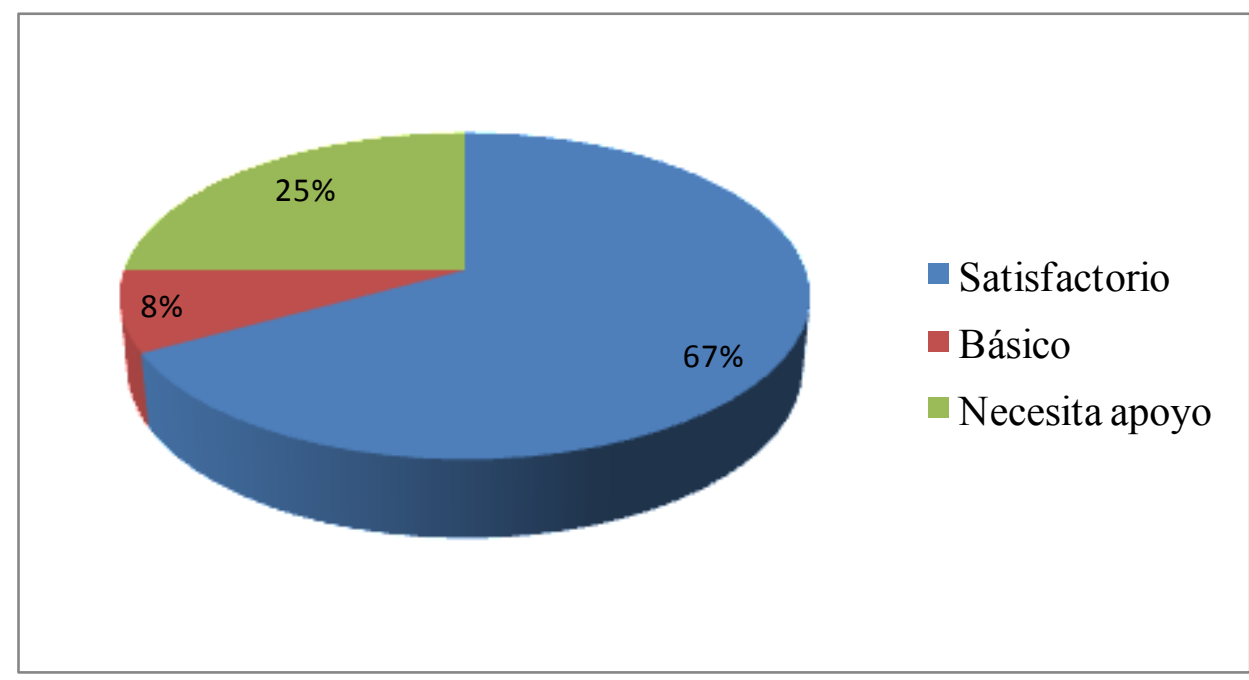

Figura 5. Taller para identificar palabras y pseudoplabras aplicado a los niños de los grados tercero y cuarto de la sede el Hatillo y Pilar y Ceibita, de la Institución Educativa Marco Antonio Quijano Rico.

Para identificar la dualidad para decodificar una palabra escrita, se entregó una listas de palabras y pseudopalabras, iniciando mediante lectura de una lista de palabras en voz alta y contabilizar el tiempo que tardan en leerlas. Esta prueba demostró que la velocidad de lectura no es la esperada, ya que el $75 \%$ de los estudiantes tardó más del tiempo estipulado para la lectura de las palabras, debido a que su lectura fue netamente silábica, ya que no reconocieron las palabras de forma global sino que la realizaron letra por

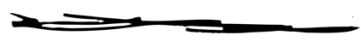

Para el desarrollo de este taller, una de las actividades realizadas consistió en dar una lista de palabras a los estudiantes, ellos debían señalar de la lista dada, cuáles eran inventadas, o reconocidas como pseudopalabras, esto con el fin de identificar el grado de decisión léxica de cada estudiante 
letra, y esto ocasionó que se demoraran y no comprendieran o relacionaran el sentido de la palabra leída.

El ejercicio se llevó a cabo con otra variación, esta consistió en dar un tiempo prudente para que el estudiante leyera la lista de las palabras, de una sílaba, dos, tres y más de tres. Al examinar los resultados (Figura 6), se pudo determinar que presentaron un avance significativo en lectura de palabras reales, pues al dar la lista ellos lograron relacionarlas con su contexto, y esto causó una lectura global ya que al asociarla con su cotidianidad su lectura es más rápida; sin embargo, los resultados con lectura de pseudopalabras demostraron que todavía persisten falencias, pues al no poder relacionarlas, su lectura fue más lenta y dispendiosa; así que, más del $75 \%$ de los estudiantes no alcanzaron a leer la totalidad de las palabras y el 25\% restante lo realizó de forma rápida, pero omitiendo letras o cambiando la palabra.

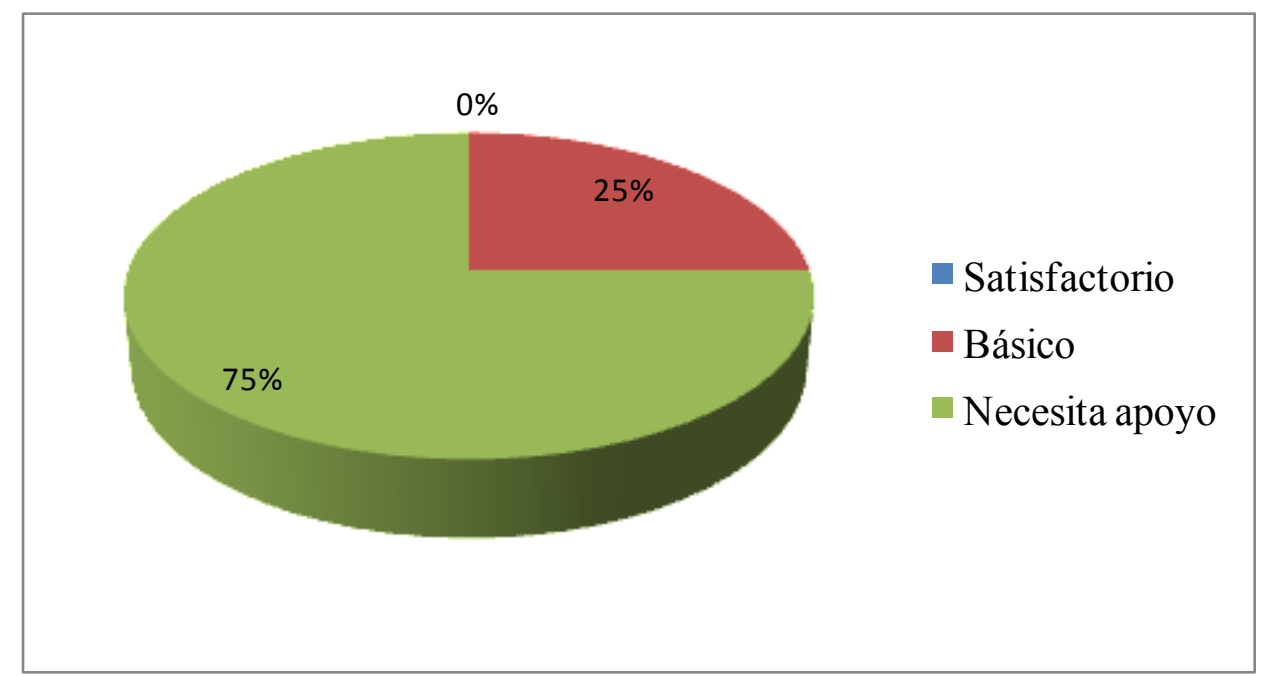

Figura 6. Taller de lectura de pseudopalabras aplicado a los niños de los grados tercero y cuarto de la sede el Hatillo y Pilar y Ceibita, de la Institución Educativa Marco Antonio Quijano Rico.

Esto refleja lo dicho por Cuetos (2010), quien afirma que para que una persona pueda realizar una buena lectura, es necesario que utilice a cabalidad las rutas establecidas, ya que la una ayuda a reconocer la palabra y su significado, es decir como un todo; mientras que la otra va relacionando la representación escrita de cada letra con su sonido y, por último, su significado.
Con base en lo anterior, se hace necesario continuar fortaleciendo estas actividades en los estudiantes, ya que para hacer una buena lectura es necesario utilizar la dualidad de vías de acceso a esta, así como lo afirma Cuetos (2010) cuando menciona que un buen lector se define como aquel que domina las dos vías, utilizando la ruta léxica de modo habitual y la fonológica cuando se encuentra ante palabras desconocidas o pseudopalabras. 


\section{Procesos Sintácticos}

Mediante la prueba de signos de puntuación, se logró un avance significativo en cuanto a la lectura en voz alta, pues los estudiantes al realizar lecturas de textos cortos tuvieron en cuenta los signos de puntuación, logrando así una mejor comprensión del texto leído. Sin embargo, cuando realizaron lecturas de formas individual, se presentaron inconvenientes para realizar debidamente las pausas y la entonación que indican los signos de puntuación en un texto, impidiendo así que se pueda realizar una lectura comprensiva, al no realizarla no se pueden identificar los papeles sintácticos de las palabras dentro de la oración y el resultado es que no entienden lo que leen.

De otra parte, al analizar los resultados de la funcionalidad de las palabras dentro de la oración, queda evidenciado que aún persisten deficiencias en los estudiantes al momento de organizar palabras dentro de una oración o completar oraciones haciendo uso de una lista de palabras, pues al no tener claro la estructura gramatical se les dificultó organizar palabras con el fin de crear una oración con sentido completo.

De acuerdo con lo descrito, se hace necesario continuar realizando ejercicios de estructura gramatical, principalmente, ya que como lo afirma García (1993).

"en la actividad lingǘstica las palabras siguen un orden sistemático construyendo expresiones lingüísticas. Un texto escrito no es una mera secuenciación de palabras independientes entre sí, muy al contrario, están estrechamente relacionadas conforme a ciertos procedimientos (reglas sintácticas) formando oraciones. En las oraciones las palabras se agrupan desempeñando ciertos papeles sintácticos" (p. 91).

Es así como resultados demuestran que, en cuanto a estructuras gramaticales, el $58 \%$, de los estudiantes aún poseen falencias, lo que los ubica en el nivel denominado "necesitan apoyo". El $38 \%$ se ubica en "categoría básica", y el $4 \%$ en "nivel satisfactorio" (Figura 7).

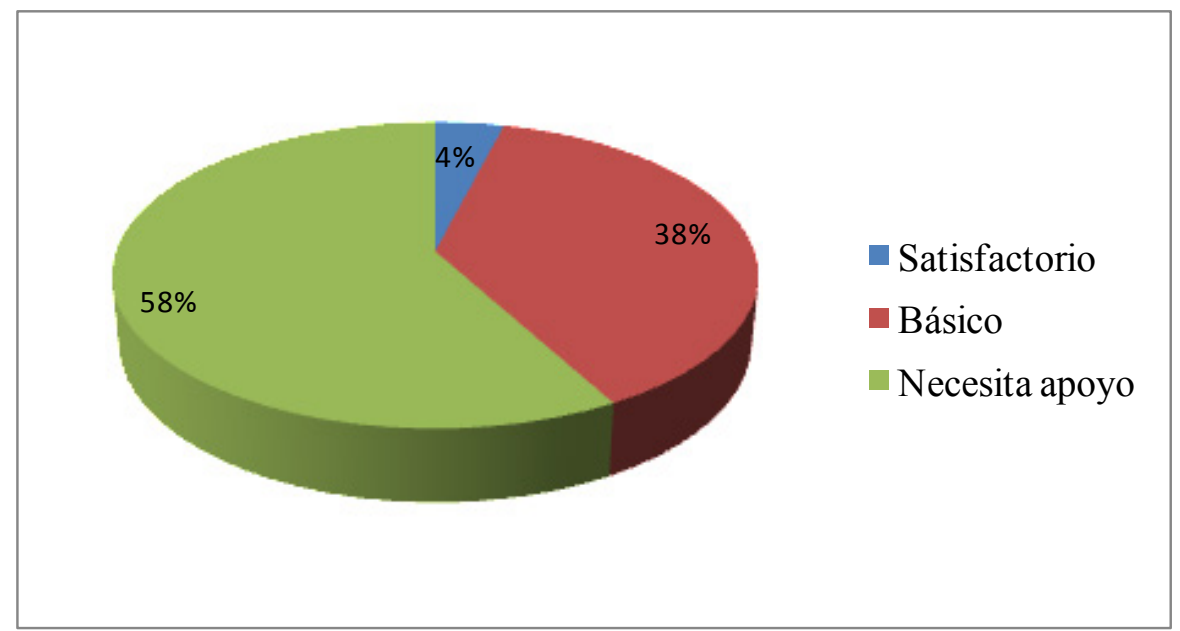

Figura 7. Taller para fortalecer la estructura gramatical aplicada a los niños de los grados tercero y cuarto de la sede el Hatillo y Pilar y Ceibita, de la Institución Educativa Marco Antonio Quijano Rico. 


\section{Procesos Semánticos}

Para fortalecer este proceso, se realizaron actividades cuyo fin fue conocer el proceso de extracción del significado y el proceso de integrar la memoria en la elaboración de inferencias. En la comprensión de oraciones, se buscó comprobar la capacidad de identificación del significado de oraciones sencillas, aquí no se requiere de memoria ni de esquemas mentales, en esta prueba se expresan órdenes muy sencillas que el niño debe realizar, hay órdenes simples, órdenes para realizar dibujos sencillos, órdenes sobre dibujos y señalar el dibujo que corresponde a la oración.

En cuanto a la prueba de estructura gramatical, se consiguió que los estudiantes se tomen el tiempo necesario para leer oraciones cortas y asociarlas con una imagen que las representaba, también se lograron avances en cuanto a seguir orientaciones descritas en una oración, es decir, realizaron las actividades sugeridas en cada una de las oraciones planteadas. Estas actividades son elementos necesarios a la hora de conseguir una comprensión en textos instructivos específicamente.

De acuerdo con lo descrito anteriormente, los resultados demuestran que los estudiantes tuvieron avances importantes, ya que el $80 \%$ logró extraer el significado de oraciones sencillas y realizar las acciones descritas en las mismas, es decir, ejecutar órdenes simples, dibujos sencillos y asociar la oración con el dibujo que le corresponde; el 20\%, aunque realizó las actividades sugeridas, lo ejecutaron con cierto grado de dificultad (Figura 8).

Para fortalecer este proceso, se realizaron actividades cuyo fin fue conocer el proceso de extracción del significado y el proceso de integrar la memoria en la elaboración de inferencias.

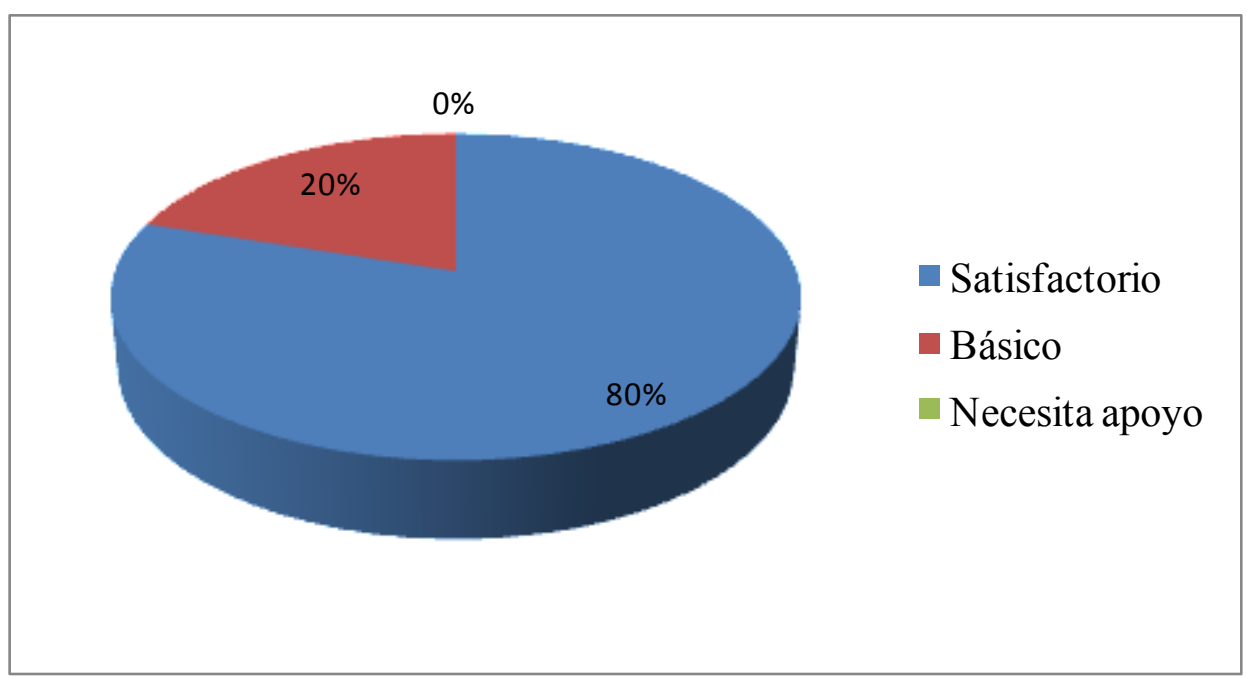

Figura 8. Taller de comprensión de oraciones aplicado a los niños de los grados tercero y cuarto de la sede el Hatillo y Pilar y Ceibita, de la Institución Educativa Marco Antonio Quijano Rico. 
Para la comprensión de textos, en donde se buscó impulsar la capacidad de los estudiantes para integrar el significado con el conocimiento, por medio de preguntas literales e inferenciales, sacadas del texto leído, los resultados arrojaron que el $75 \%$ de los estudiantes continúan presentando dificultades para extraer información de un texto, pues al no tener una lectura fluida mostraron falencias al momento de obtener el significado de textos cortos y poder integrarlos con sus conocimientos; el 20\% tienen una lectura más fluida, sin embargo, no lograron contestar preguntas de tipo inferencial, pues aseguraron que la información no estaba dentro del texto. Tan solo el 5\% presentó un mejora en cuanto a su comprensión textual, teniendo en cuenta que lograron contestar preguntas de tipo literal e inferencial, además mejoraron en cuanto a su velocidad y fluidez lectora (Figura 9). Lo descrito incide de forma negativa en la comprensión de textos, ya que Morles (1987), afirma que "Sin comprensión no hay lectura" Es por esto que, el acto de leer para comprender, no puede ser superficial, debe ser activa y exploratoria, donde se haga una conexión con conocimientos ya adquiridos, y de esta manera aporte nuevas ideas que sean importantes y con significado para el lector.

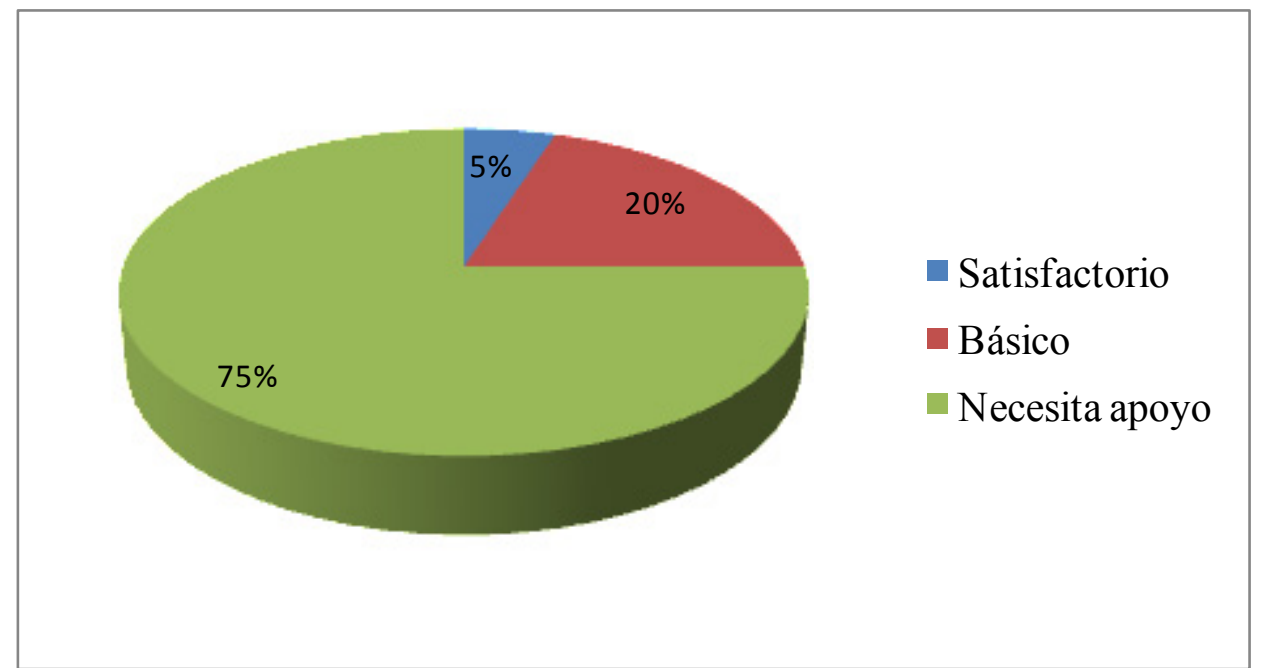

Figura 9. Taller de comprensión de textos cortos aplicado a los niños de los grados tercero y cuarto de la sede el Hatillo y Pilar y Ceibita, de la Institución Educativa Marco Antonio Quijano Rico.

\section{Evaluación}

Partiendo de la premisa contemplada en la evaluación en cuanto a si los talleres de intervención pedagógicas tuvieron influencia significativa en el fortalecimiento del proceso lector, se puede afirmar que dichas actividades lograron mejorar falencias identificadas en el diagnóstico, y se convierten en un punto de partida importante para continuar desarrollando actividades de forma transversal en la institución educativa, que conlleven a ser incluida dentro de las actividades pedagógicas desarrolladas en la institución, que tengan un espacio y tiempo pertinente para lograr mitigar las dificultades que se presentan a nivel lector. 
Por lo descrito anteriormente, se observan cambios notorios y significativos a pesar de la limitación del tiempo para la intervención pedagógica, pues se logró en primera medida identificar el orden lógico y coherente que permiten conocer por parte de los docentes una estrategia pedagógica y metodológicamente organizada, para ser adoptada como uno de las rutas al cual se puede seguir para conseguir que los estudiantes mejoren en su proceso lector. Por otra parte, se consiguió adaptar herramientas pedagógicas creativas que favorecen en los estudiantes el desarrollo de procesos cognitivos de forma conjunta, y que le apunten a un solo objetivo principal, como lo es el de mejorar su nivel de comprensión lectora en el nivel inferencial.

Es así como, al analizar los resultados obtenidos en la prueba inicial y final, se puede afirmar que aunque el tiempo fue una limitante importante se lograron avances en los estudiantes, uno de estos y tal vez el menos desarrollado por los docentes, fue conseguir preparar en primera medida los movimientos oculares de los estudiantes, ya que este es un punto de partida importante que va a repercutir en el buen desarrollo de los demás procesos, debido a que, como lo afirma Parra (2012), existe una correlación muy significativa entre los movimientos sacádicos y la velocidad y comprensión lectora.

En ese orden de ideas, se logró además superar falencias en cuanto reconocimiento de fonemas de forma gráfica y fonéticamente, los cuales intervienen de forma directa en el siguiente proceso, en el cual se logró que los estudiantes superen dificultades en la lectura y reconocimiento de palabras reales e inventadas, y verificar la ruta que poseen los estudiantes al momento de leer. Igualmente, se evidenciaron avances en cuanto a comprensión de oraciones sencillas y se propiciaron acciones encaminadas a continuar fortaleciendo los procesos sintácticos y semánticos, en los cuales los avances no fueron tan notorios, ya que estos poseen un nivel más complejo y se hace necesario contar con un tiempo más prolongado con el fin de mostrar resultados más relevantes. (Figura 10).

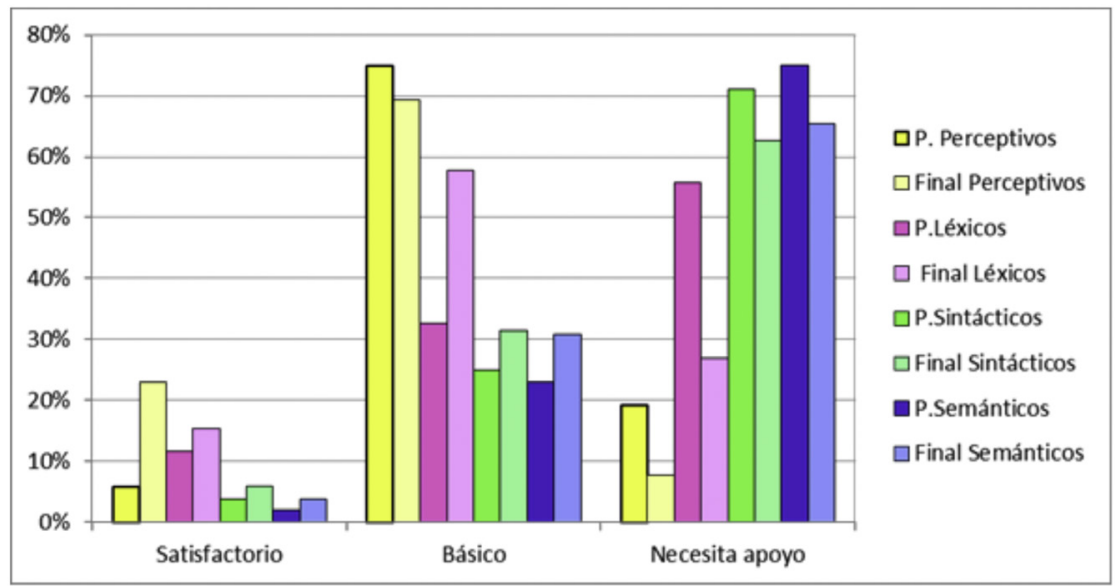

Figura 10. Comparativo taller diagnóstico inicial y final aplicado a los niños de los grados tercero y cuarto de la sede el Hatillo y Pilar y Ceibita, de la Institución Educativa Marco Antonio Quijano Rico. 


\section{Reflexiones finales}

Los resultados encontrados invitan a reflexionar sobre que el método que se utiliza para la comprensión lectora no se centra en las oraciones, en todas sus formas, como son la activa, pasiva o de complemento focalizado, esto hace ver que el modelo comunicativo, que pide el MEN, no contribuye a dar solución al problema de comprensión lectora de nuestro país, ya que los resultados que arrojan las pruebas externas hacen ver que los estudiantes están por debajo del promedio normal.

Por otra parte, la batería PROLEC de evaluación de los procesos lectores, es un valioso instrumento que nos permite detectar a los estudiantes que presentan deficiencias en alguno de los procesos lectores, teniendo en cuenta nuestros resultados todos nuestros alumnos presentan dificultades, sobre todo en los procesos sintácticos y semánticos. Esto nos da una respuesta clara de los preocupantes resultados en las evaluaciones externas.

La lectura o el hecho de aprender a leer, es la segunda etapa cognitiva por la que pasa el niño, como lo refiere el psicólogo González-Moreira et al. (2002) en un video sobre la lectoescritura temprana, al mencionar que la primera etapa es aprender a hablar, es decir, el aprendizaje del lenguaje oral, por lo tanto, leer y comprender lo que se lee va directamente relacionado con un aprendizaje optimo del idioma materno, al igual el niño que tenga dificultades en la comprensión de textos los lleva a ser analfabetos funcionales, es decir, una persona que está alfabetizada, que ha estado escolarizado, que sabe escribir y leer, pero que tiene grandes dificultades para utilizar correctamente la lectura como instrumento para desarrollar sus aprendizajes.

Es de conocimiento que saber leer, es la clave para que el niño amplíe sus conocimientos, pero no tendrá acceso a este si no comprende lo que lee. Por esto, es vital que no solo las políticas educativas diseñen estrategias que permitan que la enseñanza, sino que también Cañizalez y Benavides (2016) los maestros fomenten diseños de aprendizaje que estén acordes con lo que se necesita en esta parte del campo educativo. Estas estrategias no son aplicadas en la realidad, porque según el psicólogo González-Moreira et al. (2002) desde hace aproximadamente 20 años, se viene hablando de los tipos de lectores, de niveles de lectura, de la relación existente entre el lenguaje oral y escrito, quien asegura que el niño será un lector autónomo y competente si se le alfabetiza en su lengua materna, para que, de acuerdo con González-Moreira et al. (2002), cuando ya se domine la lengua de origen, se inicie con el aprendizaje de un nuevo idioma.

Es importante entender que, el proceso de comprensión de un texto es diferente para cada lector ya que cada persona asume e interpreta de diferente manera de acuerdo con el lector y a sus conocimientos, así es que, si no se entiende lo que se lee, se entenderá únicamente lo que aparece en el texto.
Es de conocimiento que saber leer, es la clave para que el niño amplíe sus conocimientos, pero no tendrá acceso a este si no comprende lo que lee. 


\section{Conclusiones}

Se evidenció que la familia y la institución educativa están en la obligación de fortalecer los procesos de lectura en los niños. Sin embargo, corresponde principalmente a la institución junto con sus docentes la función de impartir a los niños un espíritu lector, que les permita mejorar sus procesos necesarios para hacer una lectura efectiva. La implementación de escenarios donde los estudiantes puedan desarrollar un pensamiento crítico y reflexivo, puede convertirse en un buen punto de partida.

Con la realización del grupo focal y la entrevista a padres de familia, se logró caracterizar el contexto socio-cultural y los espacios con los que cuenta cada estudiante en su hogar para fortalecer sus procesos de lectura. Estos instrumentos permitieron deducir que los hogares de los estudiantes objeto del estudio, no cuentan con material que fortalezca los procesos adquiridos en la escuela, sumado a que el grado de acompañamiento por parte de sus padres es casi nulo.

En el ámbito escolar, se disfruta de diferentes textos donde el estudiante debe comprender y aprender de ellos. Dentro de los saberes previos que debe tener un niño a la hora de leer para aprender, se debe considerar el conocimiento y uso del género y la estructura de los textos. Cuando se comprende un texto, se realiza la interacción entre las características del lector y del texto, dentro de un contexto y las prácticas culturales letradas. Si la familia no aporta al proceso educativo, se evidencia un nivel básico en los estudiantes y una desmotivación hacia la lectura.
Después de la aplicación del proyecto de investigación, se puede afirmar que validamos su efectividad, ya que, al desarrollarlo, los estudiantes lo realizaron con agrado, y como los talleres de intervención se enfocaron a fortalecer las falencias detectadas en el diagnóstico, fueron significativos y productivos para ellos.

De igual forma, se logró evidenciar que con cada actividad aplicada para fortalecer el proceso en el que estaban fallando, mejoraron su desempeño, pues al identificar la falencia permitió trabajar sobre la misma y así empezar a superarla para realizar un buen proceso lector y llegar a tener comprensión lectora que es nuestra finalidad. Por lo anterior, se puede concluir que al instaurar la guía PROLEC para trabajar los cuatro procesos lectores, como vienen organizados y con tiempo suficiente para desarrollar cada uno de ellos, se pueden demostrar avances notorios en la comprensión lectora de los estudiantes; es decir que diseñar la práctica pedagógica, se establecieron escenarios de diálogo con los escolares con el fin de leer sus necesidades e intereses y orientar sus búsquedas (Samáca, 2016, p. 89).

Respondiendo a los objetivos planteados en el presente proyecto, se formulan las siguientes estrategias, con el fin de lograr que los estudiantes lleguen a tener una comprensión lectora óptima para su buen desempeño académico:

Recomendar a los docentes seguir los procesos de lectura de Fernando Cuetos como guía para afianzar la lectura de lo más simple a lo más complejo y lograr lectura comprensiva en los estudiantes. 
Conocer y aplicar guías que contribuyan a fortalecer las deficiencias presentadas en alguno de los procesos de lectura, para poder vencerlas y continuar el proceso con el fin de lograr la comprensión lectora, y así contribuir de manera eficiente al desarrollo del aprendizaje en los niños.

Verificar si al implementar los talleres de intervención, si están ayudando a los estudiantes a superar las falencias encontradas en el proceso lector.

Es importante recomendar que el material didáctico que se utilice para trabajar los procesos de lectura debe ser acorde con las necesidades y dificultades que presentan los estudiantes, para que se motive, dinamice, refuerce y evalúe la actividad.

\section{Referencias}

Bravo, Luis. (1996). Psicología de las Dificultades del Aprendizaje Escolar. Chile: Ed. Universitaria.

Castellanos, Yeimy, Lozano, Teresa y Osorio Mónica (2013). La literatura infantil como estrategia pedagógica para generar aprendizajes significativos en los procesos de lectura. (Trabajo de grado Licenciatura en Pedagogía Infantil). Universidad del Tolima.

Chambers, A. (2008). Conversaciones. Escritos sobre la literatura y los niños. España: Fondo de Cultura Económica de España.

Cuetos, F., (2010), Psicología de la lectura. P. 29.Elliott, J. (2000). La Investigaciónacción en educación. Ediciones Morata, S.L.

Cañizález Mesa, N. E., \& Benavides Rozo, F. A. (2018). La didáctica como herramienta de la reflexión docente. Educación Y Territorio, 6(11), 105 - 145. Recuperado a partir de https://jdc.edu.co/revistas/index.php/reyte/article/ view/48

FEO, E. (2010). El cuento como estrategia pedagógica para generar aprendizajes significativos en los procesos de lectura en el grado primero de la institución educativa San Luis sede Bellavista de Florencia Caquetá. (Trabajo de grado). Universidad de la Amazonia, Florencia, Colombia.

Ferreiro, E., \& Teberosky, A. (1979). Leer no es descifrar; escribir no es copiar. En los sistemas de escritura en el desarrollo del niño. (P. 344-353). México: Siglo XXI.

Ferreiro, E. y Teberosky, A. (2005). Los sistemas de escritura en el desarrollo del niño. México: Siglo XXI. P. 48.

García, E. (1993). Didáctica, La comprensión de textos. Modelo de procesamiento y estrategias de mejora.

González, Moreira, R., Molinari, M., Pinzás, J., Crawford, A., González, A., Ramírez, E., Rincón, G. y PÉrez, M. (2002). Lectura Comprensiva Temprana. 
Para que leamos desde la infancia, mucho más mejor. Perú: Ministerio de Educación del Perú.

Jenkinson, M.D. (1976). “Modos de enseñar”, en Staiger, R.C. (comp.), La eneñanza de la lectura, Buenos Aires, Huemul. Recuperado de: https://revistas.lasalle. edu.co/index.php/ap/article/download/1048/953/

Kemmis, S. y McTaggart, R. (1988). Investigación Acción Educativa (IAE).

LEÓN, J.A. (2004). ¿Por qué las personas no comprenden lo que leen?. Psicología Educativa, 10-(2), 101-116.

Mariño Díaz, L., Pulido Cortés, O., \& Morales Mora, L. (2016). Actitud filosófica, infancia y formación de maestros. Praxis \& Saber, 7(15), 81-101. https://doi.org/10.19053/22160159.v7.n15.2016.5724

Martínez-Bernal, J., Sanabria-Rodríguez, L., \& López-Vargas, O. (2016). Relaciones entre logro de aprendizaje, automonitoreo, estilo cognitivo y estilos de aprendizaje en estudiantes de medicina. Praxis \& Saber, 7(14), 141 - 164. https://doi.org/10.19053/22160159.5221

Morles, A. (12 de octubre de 1987). Niveles de lectura. Recuperado el 27 de agosto de 2016, de favio-nivelesdelectura.blogspot.com

Organización para la cooperación y el desarrollo económico (OCDE) (2009). La Competencia Lectora. Recuperado de: www.juntadeandalucia.es/educación/ portal/web/web/portallibroabiero.

Phillips, B. M., \& Lonigan, C. J. (2009). Variations in the home literacy environment of preschool children: A cluster analytic approach. Scientific Studies of Reading, 13(2), 146-174.

SAMACÁ Bohórquez, I. (2016). El espíritu científico en la primera infancia. Praxis \& Saber, 7(13), 89 - 106. https://doi.org/10.19053/22160159.4167

SMith, C. B. (1989). La enseñanza de la lecto-escritura: un enfoque interactivo, Madrid, Aprendizaje Visor. Recuperado de: https://revistas.lasalle.edu.co/ index.php/ap/article/download/1048/953/

SolÉ, IsABel. Estrategias de lectura, 8a . Ed., Madrid, Graó, 1998, p.69.

SolÉ, IsABEL. Estrategias de lectura, Barcelona, Graó, 1994, pág. 18.

SolÉ, IsABel. Estrategias de lectura, Barcelona, Graó, 1995, pág. 17.

Strang, R. (1965). Procesos del aprendizaje infantil, Buenos Aires, Paidós. Recuperado de: https://revistas.lasalle.edu.co/index.php/ap/article/ download/1048/953/

Teberosky, A. Los Sistemas de escritura en el desarrollo del niño. México. Editores Siglo Xxi. 22 Edición 2005.

Touriñán, J.M. La Significación del Conocimiento de la Educación. P.83-84.

Vygotsky, L. S. (1979). El desarrollo de los procesos psicológicos superiores. Barcelona: Grijalbo. 